\title{
Strained InAsN/InGaAs/InP multiple quantum well structures grown by RF-plasma assisted GSMBE for mid-infrared laser applications
}

\author{
D.-K. Shih, H.-H. Lin and Y.-H. Lin
}

\begin{abstract}
The authors report the growth, structural and optical characteristics of strained 10-period $\operatorname{InAs}_{1-x} \mathrm{~N}_{x} / \ln _{0.53} \mathrm{Ga}_{0.47}$ As multiple quantum well (MQW) structures on InP substrates grown by gas-source molecular beam epitaxy. Atomic nitrogen was generated using a RF-plasma cell. Double crystal X-ray diffractometer (DXRD) measurements indicated that adding $\mathrm{N}$ to the InAs layer reduced the net compressive strain of the MQW. The highest nitrogen composition obtained in this study was $19.5 \%$. It was also found that the incorporation of nitrogen resulted in red-shifted photoluminescence (PL) emission energy of the QWs. However, increased nitrogen composition broadened the DXRD linewidth and degraded PL intensity. The very broad PL linewidth might be related to alloy inhomogeneity. Finally, ridge waveguide lasers with different periods $(n=2-8)$ of InAs ${ }_{0.97} \mathrm{~N}_{0.03} /$ InGaAs QWs as the gain medium were fabricated. A device with four QWs gave the best performance and demonstrated pulsed oscillation up to $260 \mathrm{~K}$ at an emission wavelength of $2.38 \mu \mathrm{m}$ with a threshold current density of $3.6 \mathrm{kA} / \mathrm{cm}^{2}$. This indicates the potential of InAsN as a material for mid-infrared applications.
\end{abstract}

\section{Introduction}

Many spectroscopic and medical applications require lasers operating within the $2-3 \mu \mathrm{m}$ spectral range. Traditionally, such lasers have been developed in InGaAsSb/ $\mathrm{AlGaAsSb}$ material systems lattice matched to $\mathrm{GaSb}$ substrates [1]. However, the development of Sb-based material systems is handicapped by some very undesirable properties. GaSb compounds are difficult to etch, they have low thermal conductivity and dissociate at low temperatures. Because of the superior quality of InP substrates over $\mathrm{GaSb}$ substrates and the mature growth and processing technology of the InP alloy system, compressively strained In(Ga)As quantum well structures have been investigated as an alternative approach $[2,3]$ in this spectral range. In addition, it is noteworthy that the novel III- $(\mathrm{N}, \mathrm{V})$ alloy system has recently been proposed as a possible candidate for the active region of long-wavelength laser diodes [4, 5]. The advantage of these materials lies in the huge bowing parameters induced by the large differences in atomic sizes and electronegativities of $\mathrm{N}$ and other group $\mathrm{V}$ atoms. Among these mixed group- $V$ nitride alloys, the ternary alloy InAsN could be a very promising material for mid-infrared optoelectronic devices.

Recently, the authors demonstrated a $2.2 \mu \mathrm{m}$ InAs/InGaAs/InP highly strained multiple quantum wells

\section{(1) IEE, 2003}

IEE Proceedings online no. 20030389

DOI: 10.1049/ip-opt:20030389

Paper first received 18th January and in revised form 7th November 2002 The authors are with the Graduate Institute of Elcctronics Engineering and Department of Electrical Engineering, National Taiwan University, Taipei, Taiwan, Republic of China
(MQW) laser diode [6]. Longer emission wavelengths can be achieved with InAs QWs by increasing the quantum well thickness. However, the onset of plastic relaxation at a critical thickness of pseudomorphic growth limits optoelectronic quality. It is well known that the strain compensation technique, where the barrier layer is strained in the opposite sense to the well layer, has often been used to avoid this problem. These techniques are useful for InGaAs(P) MQWs with strain less than 1\%. For layers with strain exceeding $1 \%$, this technique is not always effective [7-9].

Previously it was found that there is no significant improvement in the structural and optical quality of strain-compensated InAs/InGaAs MQWs [6]. A novel material system InAsN/InP could circumvent the critical thickness limitation. Using InAsN to replace InAs can alleviate the critical thickness limitation on the quantum well because of its small lattice constant, and can also further reduce the bandgap energy of the quantum well because of its huge bowing effect. These two features suggest the possibilities of pushing the wavelength of lasers on InP substrates into the longer infrared range. In an earlier publication [10], InAsN/InGaAsP quantum wells on InP substrates with a $10 \mathrm{~K}$ photoluminescence (PL) peak wavelength as long as $2.6 \mu \mathrm{m}$ were described. However, only very limited attention was given to this material because previous studies had demonstrated problems of phase separation and immiscibility in the growth of InAsN with high nitrogen content. Nonetheless, there are no existing definitive results on the synthesis of this alloy $[11-13]$. In this study, the growth and PL of a variety of strained $\operatorname{InAs_{1-x}} \mathrm{N}_{x} / \operatorname{In}_{0.53} \mathrm{Ga}_{0.47} \mathrm{As}$ MQWs have been investigated. $\operatorname{In}_{0.53} \mathrm{Ga}_{0.47} \mathrm{As}$ lattice-matched to $\mathrm{InP}$ substrate will be referred to as InGaAs throughout the text. It is demonstrated that the $\operatorname{InAs} s_{1-x} \mathrm{~N}_{x} /$ InGaAs QW material system is suited for emission above $2 \mu \mathrm{m}$. 
Preliminary performance of InAsN MQWs laser diodes is also reported.

\section{Experiments}

All InAs(N) MQW samples for this study were grown on semi-insulating (001) InP substrates using a VG V80H gassource molecular beam epitaxy (GSMBE) system. Besides the elemental In and $\mathrm{Ga}$ sources and thermally cracked $\mathrm{AsH}_{3}$ and $\mathrm{PH}_{3}$ sources, an EPI UNI-bulb RF plasma source was used to generate active $\mathrm{N}$ species. After thermally cleaning the InP substrate at $500^{\circ} \mathrm{C}$ under $\mathrm{P}_{2}$ flux, a $0.3 \mu \mathrm{m}$ thick $\ln _{0.53} \mathrm{Ga}_{0.47} \mathrm{As}$ layer was first deposited as a buffer. High-brightness mode $\mathrm{N}_{2}$ was then ignited for growth of the subsequent 10-period MQW structure that comprises $20 \mathrm{~nm}$ thick $\operatorname{In}_{0.53} \mathrm{Ga}_{0.47} \mathrm{As}$ barriers and $3 \mathrm{~nm}$ thick InAsN wells. Besides the InAsN samples, a reference InAs $/ \ln _{0.53} \mathrm{Ga}_{0.47} \mathrm{As}$ MQW was also grown under the same growth conditions except the irradiation of active $\mathrm{N}$ species. A low growth temperature of $400^{\circ} \mathrm{C}$ was chosen for the MQWs to avoid dislocation generation [14] and enhance nitrogen incorporation [10]. The RF plasma cell was operated at $180 \mathrm{~W}$ with a varying nitrogen flow rate from 0.1 to $0.58 \mathrm{sccm}$. A mechanical shutter in front of the plasma source was used to control the illumination of nitrogen species. The RF power was turned off immediately after QW growth. The growth rate of InAs was $1.5 \mu \mathrm{m} / \mathrm{h}$ and the $\mathrm{As} / \mathrm{In}$ ratio was close to 2 . These conditions were selected based on previous investigation of two-period InAs QW structures [6]. Additionally, there were no growth interruptions at the hetero-interfaces of the QW structure.

The laser structure used in this study was a separate confinement heterostructure $(\mathrm{SCH})$ with $\operatorname{InAs} \mathrm{s}_{0.97} \mathrm{~N}_{0.03} /$ $\ln _{0.53} \mathrm{Ga}_{0.47} \mathrm{As}$ strained MQW active medium. Three device structures with different MQW periods $(n=2,4$, and 8) were grown. The $\operatorname{In} A s_{0.97} \mathrm{~N}_{0.03}$ wells were $3 \mathrm{~nm}$ thick and separated by $40 \mathrm{~nm}$ thick $\operatorname{In}_{0.53} \mathrm{Ga}_{0.47}$ As barriers. After theoretical calculations of the optical confinement factor for QWs using a straightforward $2 \times 2$ matrix approach proposed by Zou et al. [15], the total thickness of the active region was designed to be $380 \mathrm{~nm}$. The active layer consisted of a four- and a two-period QW, the two outside InGaAs layers being $124 \mathrm{~nm}$ thick and $169 \mathrm{~nm}$ thick, respectively. To begin the growth, a $0.5 \mu \mathrm{m}$ thick $\mathrm{n}^{+}$InP buffer layer was deposited on the $\mathrm{n}^{+}$-InP substrate; both the buffer and substrate serve as n-cladding layer. The active MQW structure was then grown, followed by deposition of the p-cladding layer, a $1.7 \mu \mathrm{m}$ thick p-type InP with the doping concentration increased from $2 \times 10^{17} \mathrm{~cm}^{-3}$ to $8 \times 10^{18} \mathrm{~cm}^{-3}$. Finally, a $0.1 \mu \mathrm{m}$ thick $\mathrm{p}^{+}$-InGaAs contact layer was deposited. $\mathrm{Si}$ and $\mathrm{Be}$ were used as dopant sources. For InAsN growth, the RF power was fixed at $180 \mathrm{~W}$ and nitrogen flow rate was $0.1 \mathrm{sccm}$. The cladding and buffer layers were grown at $460^{\circ} \mathrm{C}$, while the InAsN/InGaAs MQW was grown at $400^{\circ} \mathrm{C}$.

In previous studies [16], it has been shown that after rapid thermal annealing (RTA), both the PL intensity and linewidth of InAsN quantum wells are improved. Therefore, post-growth rapid thermal annealing was at $575^{\circ} \mathrm{C}$ for 20 min under $\mathrm{N}$ ambient. Ridge waveguide lasers with a $6 \mu \mathrm{m}$ wide active region were fabricated using wet chemical etching and metallisation techniques.

The nitrogen compositions of InAsN quantum wells were determined by fitting the (004) double crystal X-ray diffractometer (DXRD) spectra using a dynamic simulation program, RADS (Bede Scientific, UK). Low-temperature photoluminescence (PL) was used to evaluate the optical quality of the MQW. The $514.5 \mathrm{~nm}$ line of an $\mathrm{Ar}^{+}$laser was used as the excitation source and samples were mounted on a closed cycle helium cryostat for low-temperature measurements. The luminescence was collected by two $\mathrm{CaF}_{2}$ condenser lenses and dispersed by a SPEX $500 \mathrm{M}$ monochromator into a liquid-nitrogen-cooled HAMAMATSU P3357-02 InSb photodiode.

\section{Results and discussion}

\subsection{Characteristics of strained $\ln A s_{1-x} N_{x} / \ln G a A s$ MQWs structures}

Fig. 1 shows the DXRD spectra of InAsN/InGaAs MQWs grown at different nitrogen flow rates. The well and barrier widths were $3 \mathrm{~nm}$ and $20 \mathrm{~nm}$, respectively. As can be seen, increasing the $\mathrm{N}_{2}$ flow rate shifted the zeroth-order peak of the InAsN/InGaAs MQW towards the InP substrate peak. This reveals that adding $\mathrm{N}$ into the InAs layer reduces the net compressive strain of the system. The satellite peaks, however, are broader and weaker than those of $\mathrm{N}$-free samples. Since there is a very large atomic-size difference between nitrogen and arsenic, the large local strain from nitrogen incorporation in InAs crystal could result in inferior crystallinity, even phase separation. In fact, as the $\mathrm{N}_{2}$ flow rate increases (indicating more $\mathrm{N}$ is generated and incorporated into the $\ln A s$ ), the reflection high energy electron diffraction (RHEED) pattern observed during InAsN layer growth becomes spottier and dimmer, indicating a three-dimensional growth mode. The fitted $\mathrm{N}$ composition and corresponding $\mathrm{N}_{2}$ flow rate are also shown on the right-hand side of the Figure. It should be noted that the nitrogen composition of sample C959 is about $19.5 \%$, which is almost lattice-matched to $\operatorname{InP}$, as predicted by theory. Comparing recent report [17] concerning growing InAsN bulk on the same type of substrate, and taking into consideration the effect of different growth conditions such as $\mathrm{N}_{2}$ flow rate, plasma power and growth temperature, it

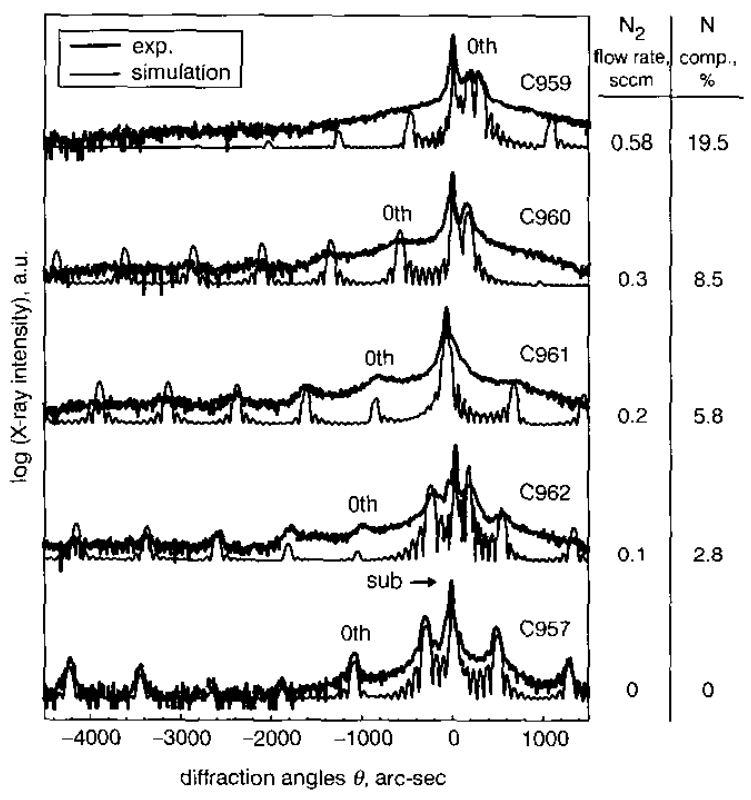

Fig. 1 DXRD spectra of InAsN/InGaAs MQW's

$\mathrm{N}$ composition of InAsN and corresponding $\mathrm{N}_{2}$ flow rate are also shown at the right-hand side of the Figure. The zeroth-order satellite peak of the InAsN/lnGaAs MQWs is marked as 0th 
was found that the incorporation of nitrogen into the InAsN QW structure is much easier than into InAsN bulk structure. In fact, the multilayer structure may stabilise the In AsN alloy by sandwiching thin layers between InGaAs 'templates'. Similar phenomena have been reported by Mendoza-Diaz et al. [18] and Hao et al. [19]. In addition, it should be noted that a strain effect might also play a significant role. The lattice mismatch between InAs and InP is $3.2 \%$. If the thickness of the InAs epilayer is below the critical layer thickness calculated from Matthews and Blakeslee's model [20] (MQW case), the incorporation of nitrogen could reduce compressive strain and thus surface free energy. On the other hand, the incorporation of $\mathrm{N}$ into relaxed InAsN bulk film does not have this advantage. This reason was given in a previous report to explain the incorporation difference between InAsN MQW grown on InP and InAs substrates [21].

The 15K PL spectra of these MQWs are shown in Fig. 2. Spectra C957-a and C957-b were measured from different regions of the same InAs/InGaAs MQW samples. Their different behaviours indicate that this sample lacks material uniformity, which might be due to the partial elastic strain relief in some regions of $\mathrm{C} 957$, although the results of X-ray diffraction can be fitted well by the simulation program. As shown in the figure, the PL wavelength red-shifts with increasing $\mathrm{N}$ composition. This clearly indicates a large bowing effect due to the incorporation of $\mathrm{N}$. In general, the greater the number of $\mathrm{N}$ atoms incorporated into $\ln A s$, the worse the crystallinity, and the weaker the PL intensity. However, as shown in Fig. 2, sample C962 has a more symmetric PL profile and higher intensity than those for C957-b, although the former has broader full width at half maximum (FWHM). The symmetric PL profile could be ascribed to better interfaces in $\mathrm{C} 962$ because of the reduced compressive strain. However, further increase of $\mathrm{N}$ composition results in

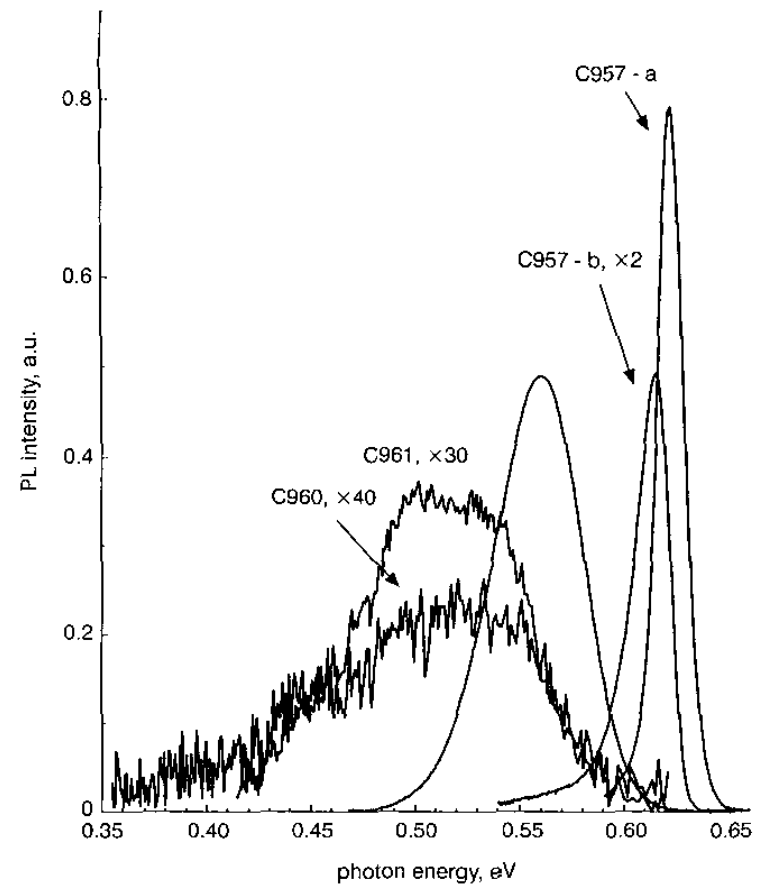

Fig. 2 Photoluminescence spectra of InAsN/InGaAs MQWs with various $N$ compositions

$T=15 \mathrm{~K}$ dramatic degradation in PL intensity. For sample C959 with the highest $\mathrm{N}$ composition, 0.195 , the PL signal is not observable. This behavior is similar to that reported previously for a InGaAsN system $[22,23]$.

Basically, degradation of optical quality might be due to nonradiative defects introduced by the small diameter $\mathrm{N}$ atoms seated on arsenic sites [4]. However, small amounts of $\mathrm{N}$ incorporation can not only reduce the high lattice mismatch between InAs and InP, but can also enhance both material uniformity and PL intensity. In addition, compared with sample C961, the PL peak energy of C960 remains nearly unchanged. A possible reason might be the band-filling effect caused by the residual free carrier concentration in samples with high nitrogen content, as previously observed in InAsN bulk samples [17]. The effect somehow compensates the nitrogen-induced bowing effect. However, the band-tail of the C960 PL profile extends to $0.38 \mathrm{eV}$, even lower than the bulk InAs bandgap energy $0.41 \mathrm{eV}$ at $15 \mathrm{~K}$.

Fig. 3 shows the $15 \mathrm{~K}$ PL spectra for InAsN/InGaAs QWs with single-period sample C1181 and 10-period sample C1183. The well thickness is $3 \mathrm{~nm}$ and the barrier is $40 \mathrm{~nm}$ thick. Growth conditions were kept the same except for QW periods. The nitrogen content of sample C1 183, obtained from DXRD spectra fitting, is about $5 \%$. Because there is no satellite peak in the X-ray diffraction pattern of a SQW structure, it is difficult to determined nitrogen composition from DXRD spectra fitting. As shown in Fig. 3, the PL peak energies are about 0.51$0.52 \mathrm{eV}(\sim 2.4 \mu \mathrm{m})$ for these two samples. Features at approximately $0.46-0.47 \mathrm{eV}$ are from atmospheric absorption. Since the PL peak energies of the two samples are very close, the nitrogen composition of $\mathrm{C} 1181$ is assumed to be almost identical to $\mathrm{C} 1183$. It is reasonable that the PL intensity of 10-period QW samples is stronger than that of a single quantum well. In addition, it should be noticed that the PL FWHM of these two samples are nearly the same,

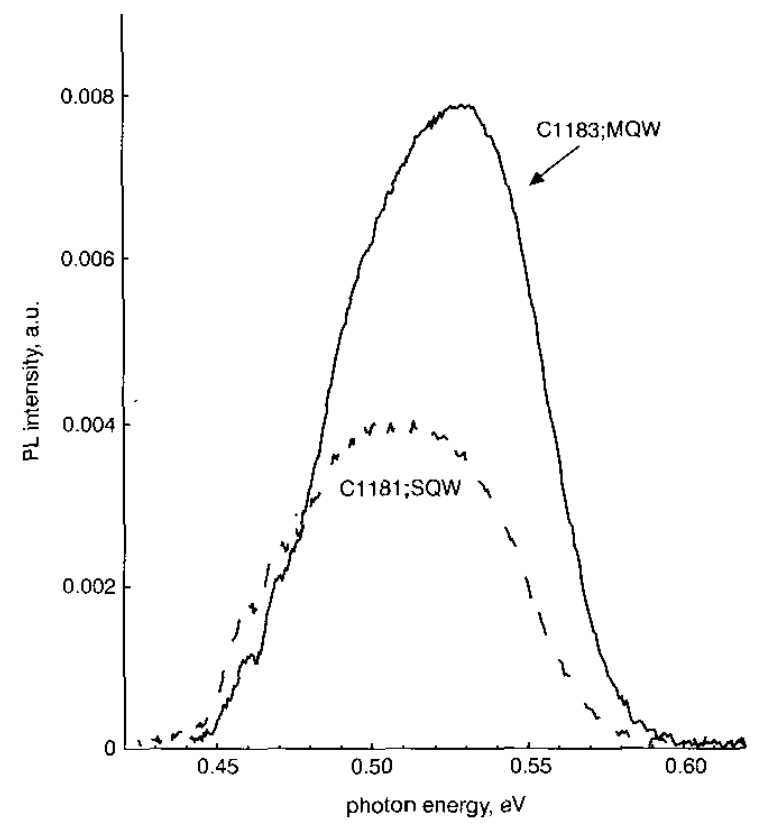

Fig. $3 P L$ spectra of InAsN/InGaAs single quantum well structure (sample C1181) and ten-period multiple quantum well structure (sample C1183)

Nitrogen compositions $\approx 5 \% ; T=15 \mathrm{~K}$ 
Table 1: Summary of PL peak energy, PL FWHM, and nitrogen composition of $\ln A s N / \ln G a A s$ QWs

\begin{tabular}{lclll}
\hline Sample No. & $\begin{array}{l}\text { OW } \\
\text { number }\end{array}$ & $\begin{array}{l}\text { Peak energy. } \\
(\mathrm{eV})\end{array}$ & $\begin{array}{l}\text { FWHM } \\
(\mathrm{meV})\end{array}$ & $\begin{array}{l}\mathrm{N} \text { comp. } \\
(\%)\end{array}$ \\
\hline C1181 & 1 & 0.513 & 85 & - \\
C1183 & 10 & 0.529 & 74 & 5 \\
\hline
\end{tabular}

about $80 \mathrm{meV}$. This result reveals that the possible origin of the anomalous huge PL FWHM of these high nitrogencontaining QW samples is due to a strong alloy inhomogeneity effect rather than well thickness fluctuation or local strain relaxation. This strong alloy inhomogeneity is difficult to eliminate by means of RTA [24]. A summary of the PL peak energy, PL FWHM, and nitrogen composition of each sample is presented in Table 1.

\subsection{Preliminary performance of InAs ${ }_{0.97} N_{0.03} /$ In GaAs/InP laser}

Fig. 4 shows 10K PL spectra of laser structures with 2, 4, and 8 QWs, after the removal of the upper contact and cladding layer. The nitrogen composition of these samples is about 3\%. In these strained InAsN/InGaAs MQWs, the effect of well number on PL intensity is noteworthy. The $10 \mathrm{~K}$ PL intensity as a function of the period of the $\ln \mathrm{AsN} / \mathrm{InGaAs}$ MQW is shown in the inset of Fig. 4. It is apparent that when the number of quantum wells rises from 2 to 4 , the PL intensity increases. However, with further increase in the number of quantum wells, the PL intensity saturates. Although the PL FWHMs of these samples are almost the same, we believe that the PL intensity saturation might be caused by strain-induced defects because the 8-QW structure has large total strain and the density of strain-related defect should depend on the total thickness of the InAsN MQW.

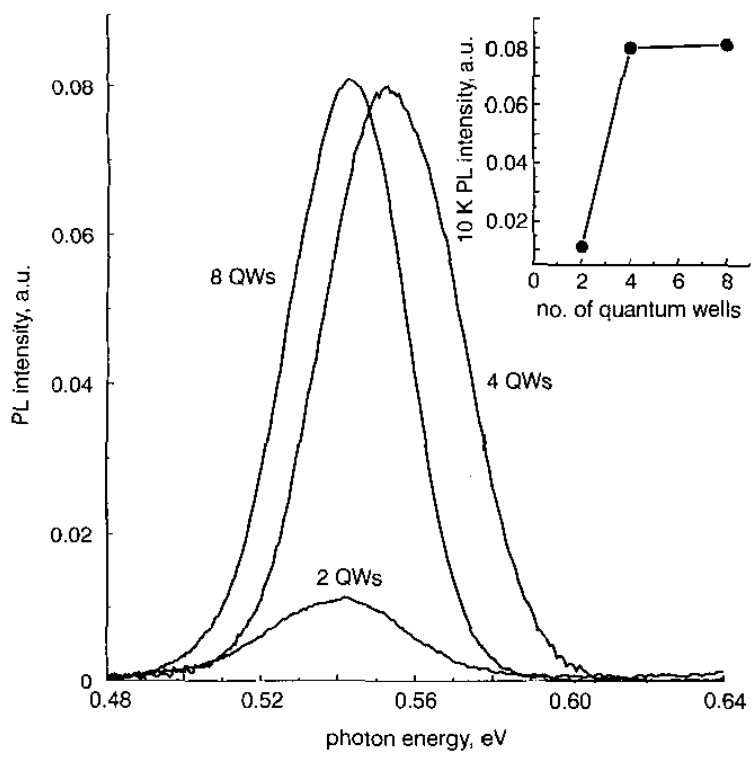

Fig. $4 P L$ spectra of laser structures with two, four and eight QWs after removal of upper contact and cladding layer

Inset shows PL intensity as a function of number of InAsN/[nGaAs QWs

$T=10 \mathrm{~K} ;$ Nitrogen compositions $\approx 3 \%$

256
The light output power versus injection current $(L-I)$ characteristics for the lasers with four QWs (length $L=942 \mu \mathrm{m})$ and eight QWs $(L=697 \mu \mathrm{m})$ are shown in Fig. $5 a$ and $5 b$, respectively. The laser diodes were measured under pulsed operation at a series of temperatures from $10 \mathrm{~K}$ to their highest operating temperature. The pulse length and repetition rate are $5 \mu \mathrm{s}$ and $500 \mathrm{~Hz}$. For the laser with four QWs, a threshold current of $203 \mathrm{~mA}$ is achieved at $260 \mathrm{~K}$, the corresponding threshold current density is $3.6 \mathrm{kA} / \mathrm{cm}^{2}$. The laser with eight QWs shows a threshold current $I_{\mathrm{th}}=66 \mathrm{~mA}$ at $200 \mathrm{~K}$, corresponding to a threshold current density of $1.6 \mathrm{kA} / \mathrm{cm}^{2}$. The slope efficiency degrades rapidly as the temperature increases. Some possible loss mechanisms are suggested. First, in this narrowgap material, Auger recombination becomes more significant at longer wavelengths and/or higher operating
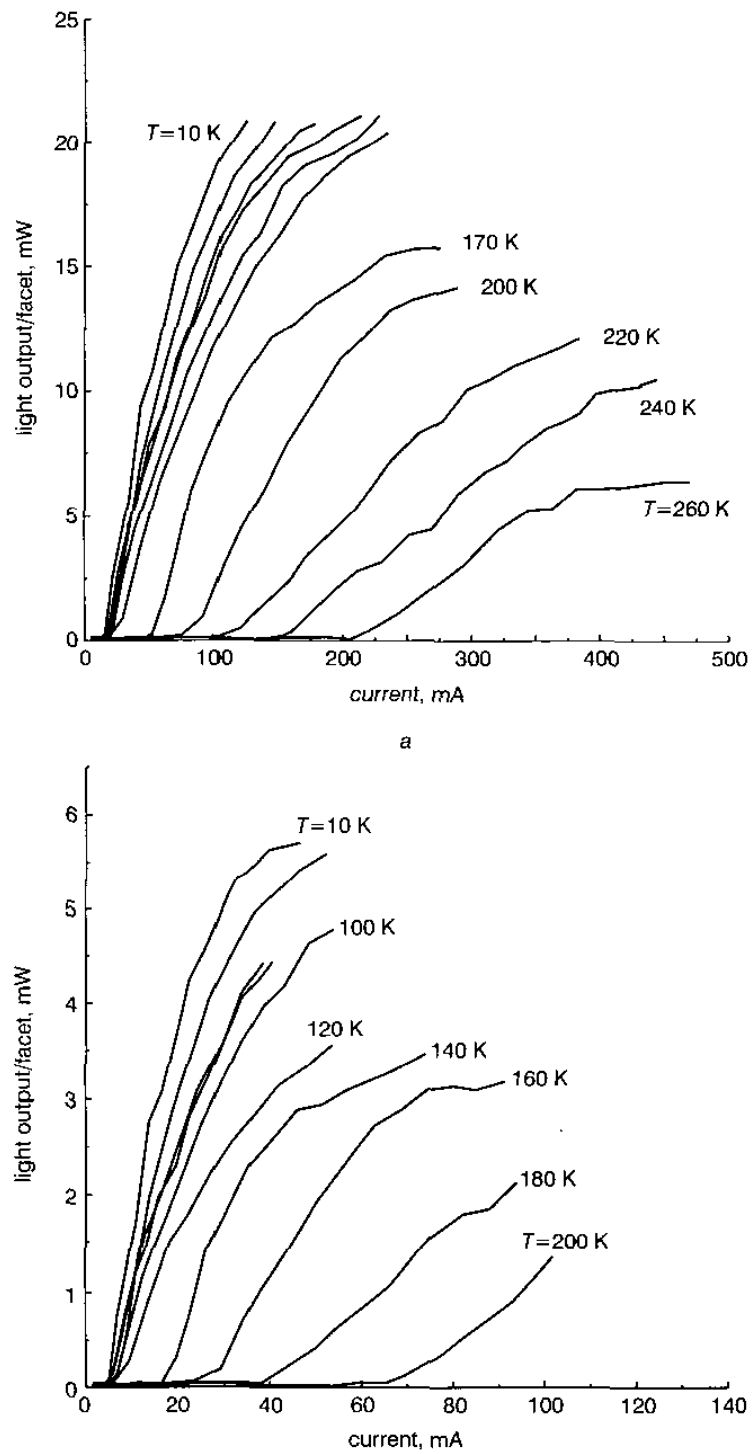

Fig. $5 L-I$ plots for InAsN/InGaAs ridge waveguide lasers measured under pulsed operation at temperatures from $10 \mathrm{~K}$ to their maximum operating temperature

$a$ Four QWs; threshold current density $3.6 \mathrm{kA} / \mathrm{cm}^{2}$ at $260 \mathrm{~K} ; N=6 \mu \mathrm{m}$; $L=942.2 \mu \mathrm{m} ; 500 \mathrm{~Hz} ; 5 \mu \mathrm{s}$

$b$ Eight QWs; threshold current density $1.6 \mathrm{kA} / \mathrm{cm}^{2}$ at $200 \mathrm{~K}$; $W=6 \mu \mathrm{m} ; L=697.2 \mu \mathrm{m} ; 500 \mathrm{~Hz} ; 5 \mu \mathrm{s}$ 

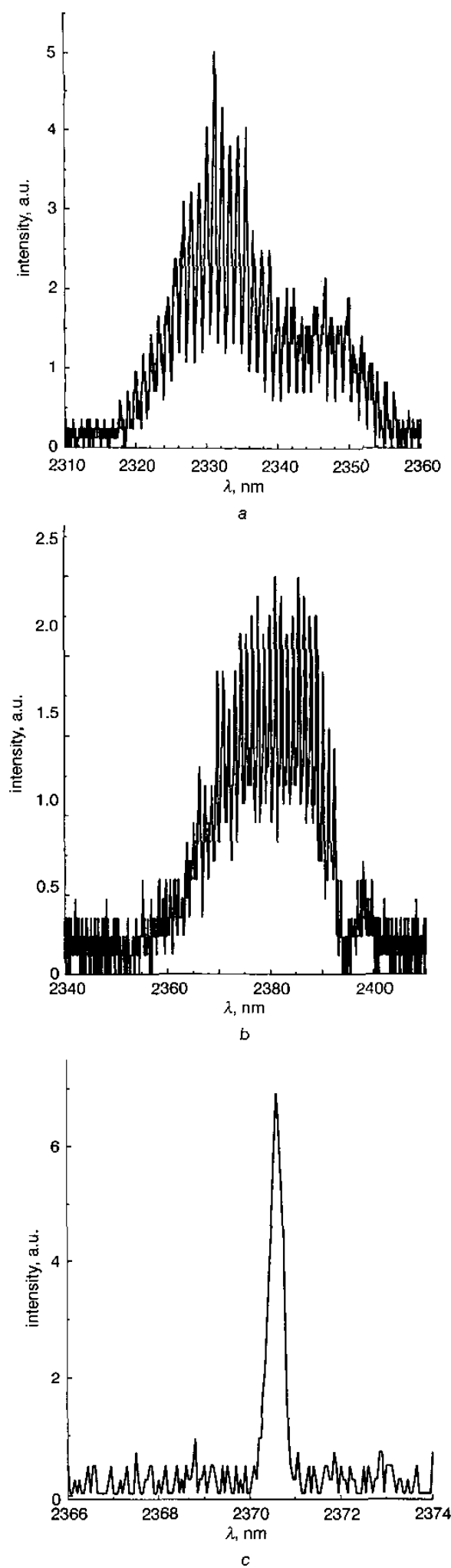

Fig. 6 Emission spectra of InAsN/InGaAs lasers under injection current $I=1.4 I_{\text {th }}$

a Four QWs: $T=200 \mathrm{~K}$

$b$ Four QWs; $T=260 \mathrm{~K}$

$c$ Eight QWs; $T=200 \mathrm{~K}$ temperature [25]. Second, because of the high nitrogen composition $(\sim 3 \%)$ in the wells, defects introduced by the small diameter nitrogen located on arsenic sites and the alloy inhomogeneity is expected to exist in InAsN even after postgrowth RTA. These defects would act as nonradiative recombinations and be thermally activated, resulting in a decrease in the luminescence efficiency [24].

The lasing spectra of a four-QW laser diode at $200 \mathrm{~K}$ and $260 \mathrm{~K}$ under pulsed injection at $I=1.4 I_{\mathrm{th}}$ are shown in Figs. $6 a$ and $6 b$, respectively. Multiple longitudinal modes are observed. The lasing spectrum of an eight-QW laser at $200 \mathrm{~K}$ is shown in Fig. $6 c$. At the maximum laser operating temperature, the peak lasing wavelength of lasers with four and eight QWs was $2.38 \mu \mathrm{m}$ and $2.37 \mu \mathrm{m}$, respectively. Both emission wavelengths are much longer than those of laser diodes using InGaAs/InP or InAsP/InP material systems previously reported. The emission wavelength peak of the eight-QW laser is longer than that of the four-QW laser at $200 \mathrm{~K}$, which is consistent with their PL behaviour at $10 \mathrm{~K}$. It is worth noting that the slope efficiency of the eight-QW laser degrades more rapidly than that of the four QW structure as the temperature increases. This can be attributed to two possibilities. First, as mentioned before, the net strain in the laser active region with eight QWs is larger than with four QWs and therefore results in a higher density of strain-related defects. Second, nonuniform carrier distribution in the $\mathrm{QW}$ region might result in deterioration in laser performance. Because of the short transport distance of the holes in the active region, the holes would be populated preferentially in the first few wells close to the p-cladding layer [26]. This will result in gain from these QWs near the p-cladding layer and losses from other wells.

Fig. 7 shows the temperature dependence of threshold current density $J_{\text {th }}$ for the $\operatorname{InAsN} / \operatorname{InGaAs} / \mathrm{InP}$ four-QW laser. By fitting the $J_{\text {th }}$ data to the equation $J_{\text {th }}(T)=$ $J_{0} \exp \left(T / T_{0}\right)$, we obtain $T_{0}=62 \mathrm{~K}$ in the temperature range $50-260 \mathrm{~K}$. The variation of lasing wavelength with

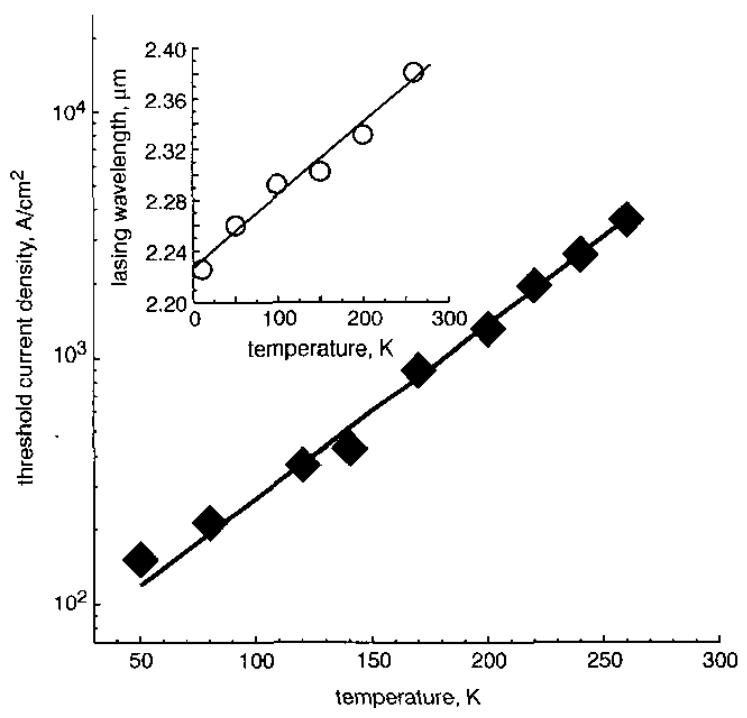

Fig. 7 Temperature dependence of threshold current density for ridge waveguide InAsN/InGaAs laser under pulsed operation

Symbols are experimental data and the solid line is a numerical fit with $T_{0}=62 \mathrm{~K}$

Inset shows variation of lasing wavelength at different operating temperatures

$W=6 \mu \mathrm{m} ; L=942 \mu \mathrm{m}$ 
operating temperature is also shown in the inset of Fig. 7. A slope of $\sim 0.59 \mathrm{~nm} / \mathrm{K}$ is measured.

\section{Conclusions}

In summary, we have studied the growth, structural and optical characteristics of strained $\ln \mathrm{As}_{1-x} \mathrm{~N}_{x} / \operatorname{InGaAs}$ MQW structures with well width $3 \mathrm{~nm}$ and nitrogen composition varied from 0 to 0.195 . InAsN MQW structures have been successfully applied to mid-infrared laser diodes. A device with a four $\operatorname{InAs} \operatorname{sig7}_{0.97} \mathrm{~N}_{0.03} / \operatorname{InGaAs}$ QW gain medium demonstrates pulsed oscillation at $260 \mathrm{~K}$ with a threshold current density of $3.6 \mathrm{kA} / \mathrm{cm}^{2}$ and an emission wavelength of $2.38 \mu \mathrm{m}$.

\section{Acknowledgments}

This work was supported by the National Science Council and the Ministry of Education of the Republic of China under Contracts NSC 90-2215-E-002-030 and 89-N-FA012-4-3, respectively.

\section{References}

l CHOI, H.K., and EGLASH, S.J.: 'High-power multiple-quantum-well $\mathrm{Ga} \ln \mathrm{AsSb} / \mathrm{AlGaAsSb}$ diode lasers emitting at $2.1 \mu \mathrm{m}$ with low threshold current density", Appl. Phys. Lett., 1992, 61,(10), pp. $1154-1156$

2 FOROUHAR, S., KSENDZOV, A., LARSSON, A., and TEMKIN. H.: 'InGaAs/InGaAsP/InP strained-layer quantum well lasers at $\sim 2 \mu \mathrm{m}$ ', Electron Lett 1992, 28, (15) pp 1431-1432

3 KUANG, G.K., BÖHIM, G., GRAU, M., RÖSEL, G., MEYER, M., and AMANN, M.-C.: '2.12 $\mu \mathrm{m}$ InGaAs-InGaAlAs-InP diode lasers grown in solid-source molecular beam epitaxy', Appl. Phys. Lett., 2000, 77, (8), pp. 1091-1092

4 KONDOW, M., KITATANI, T., NAKATSUKA, S., LARSON, M.C. NAKAHARA, K YAZAWA, $Y$, and UOMI, K. 'GaInNAs: A novel material for long-wavelength semiconductors laser', IEEE J. Sel. Top. Quantum Electron., 1997, 3, (3), pp. 719-730

5 FISCHER, M.O.. REINHARDT, M.. and FORCHEL, A.: 'Room temperature operation of GaInAsN-GaAs laser diodes in the $1.5-\mu \mathrm{m}$ range', IEEE J. Sel. Top. Quantum Electron., 2001, 7. (2), pp. 149-151

6 WANG, J.S., LIN, H.H., and SUNG, L.W.: 'Room-temperature $2.2 \mu \mathrm{m}$ InAs-hnGaAs-InP highly strained multiquantum-well lasers grown by gas-source molecular beam epitaxy'. IEEE J. Ouantum Electron. 1998 34. (10), pp. 1959-1962

7 TSUCHIYA, T., KOMORI. M., TSUNETA, R., and KAKIBAYASHI, H.: "Investigation of effect of strain-compensated structure and compensation limit in strained-layer multiple quantum wells', $J$. Cnst. Growth, 1994. 145, pp. 37i-375

8 SMITH, A.D., BRIGGS, A.T.R., SCARROTT, K., ZHOU, X., and BANGERT, U.: 'Optimization of growth conditions for strain compensated $\mathrm{Ga}_{0.32} \mathrm{In}_{0.68} \mathrm{As} / \mathrm{Ga}_{0.61} \mathrm{In}_{0.3 y} \mathrm{As}$ multiple quantum wells', Appl. Phys. Lett., 1994, 65, (18), pp. $2311-2313$
9 PONCHET, A., ROCHER, A. EMERY, J-Y, STARCJ, C and GOLDSTEIN, L.: 'Direct measurement of lateral elastic modulations in a zero-net strained GaInAsP/InP multilayer', .J. Appl. Phws., 1995, 77 (5), pp. 1977-1984

10 WANG, J.S., LIN, H.H., SUNG, L.W., and CHEN, G.R.: 'Growth of InAsN/InGaAs(P) quantum wells on $\ln P$ by gas source molecular beam epitaxy', J. Vac. Sci. Technol. B. Microelectron. Nanometer Struct., 2001, 19. (1), pp. 202-206

11 SAKAl, S., CHENG, T.S., FOXON, T.C., SUGAHARA, T., NAOI, Y., and NAOI, H.: 'Growth of InNAs on GaAs(100) substrates by molecular-beam-epitaxy", J. Cyst. Gronth, 1998, 189/190, pp $471-475$

12 BERESFORD, R., STEVENS, K.S., and SCHWARTZMAN, A.F. 'Microstructure and composition of InAsN alloys grown by plasmasource molecular beam epitaxy', J. Vac. Sci. Technol. B, Microelectron. Nanometer Struct., 1998, 16, (3), pp. 1293-1296

13 NAOI, H. NAOI. Y., and SAKAI, S.: 'MOCVD growth of InASN for infrared applications", Solid-State Electron., 1997, 41, (2), pp. 319-321

14 TOURNIE. E.. and PLOOG, K.H.: 'Surface stoichiometry, epitaxial morphology and strain relaxation during molecular beam epitaxy of highly strained InAs/InGaAs heterostructures', J. Cnst. Growth, 1994 135. pp. $97-112$

15 ZOU. W.X., CHUANG, Z.M., LAW, K.-K., DAGLl, N. COLDREN, L.A., and MERZ. J.L.: "Analysis and optimization of graded-index separate-confinement heterostructure waveguides for quantum well lasers', J. Appl. Phvs. 1991, 69. (5). pp. 2857-2861

16 WANG, I.S., and LIN, H.H.: "Growth and postgrowth rapid thermal annealing of InAs $\mathrm{N} / \mathrm{InGaAs}$ single quantum well on InP grown by gas source molecular bcam epitaxy', J. Vac. Sci. Technol. B, Microelectron Nanometer Struct., 1999, 17, (5), pp. 1997-2000

17 SHIH, D.K. LIN. H.J., SONG, L.W, CHU, T.Y., and YANG. T.R. 'Bulk InAsN films grown by plasma-assisted gas source molecular beam epitaxy*. Proceedings of 13 th Conference on Indium phosphide and related materials, IPRM 01, Nara, Japan, May 2001, pp. 555-558

18 MENDOZA-DIAZ, G., STEVENS, K.S., SCHWARTZMAN, A.F, and BERESFORD, R.: 'Feasibility of the synthesis of AlAsN and GaAsN films by plasma-source molecular beam cpitaxy', J. Cryst. Growth, 1997 , 178, pp. $45-55$

19 HAO, M. SAKAI, S. SUGAHARA, T. CHENG, TS, and FOXON, C.T.: 'Transmission electron microscopy in investigation of InNAs on GaAS grown by molecular beam cpitaxy", J. Cryst. Growth 1998. 189/190, pp. $481-484$

20 MATTHEWS, J.W., and BLAKESLEE, A.E.: 'Defects in epitaxial multilaycrs'. .J. Crowt. Grouth, 1974, 27, op. 118-125

21 WANG, J.S. LIN, H.I.H. SUNG, L.W, and CHEN, G.R.: 'Growth and characterization of InAsN alloys'. Proceedings of ' 2th Conference on Indium phosphide and related materials. IPRM 00, May 2000, Williamsburg, USA, pp. 549-552

22 SAITO, H., MAKIMOTO, T., and KOBAYASHI, N.: "MOVPE growth of strained lnGaAsN/GaAs quantum wells', J. Chst. Growth, 1998 195 , pp. $416-420$

23 XIN, H.P., and TU, C.W: 'GainAsN/GaAs multiple quantum wells grown by gas-source molecular beam epitaxy'. Appl. Phis. Lett., 1998. 72 , (19), pp. $2442-2444$

24 CHEN, G.R.. LIN, H.H., WANG, J.S., and SHIH, D.K.: 'Optical

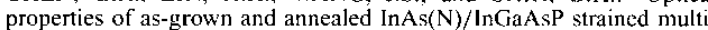
ple quantum wells', J. Appl. Phvs., 2001. 90, (12), pp. 6230-6235

25 COLDREN, L.A., and CORZINE, S.W.: 'Diode lasers and photonic integrated circuits (Wiley Interscience. New York. 1995), Chap. 4

26 YAMAZAKI, H. TOMITA, A. YAMAGUCHI, M., and SASAKI, Y Evidence of nonuniform carrier distribution in multiple quantum well lasers', Appl. Phys. Lett., 1997, 71, (6), pp. 767-769 